\title{
Effect of Television Viewing at Mealtime on Food Intake After a Glucose Preload in Boys
}

\author{
NICK BELLISSIMO, PAUL B. PENCHARZ, SCOTT G. THOMAS, AND G. HARVEY ANDERSON
}

\begin{abstract}
Department of Nutritional Sciences [N.B., P.B.P., G.H.A.], Department of Paediatrics [P.B.P.], Faculty of Medicine, University of Toronto, Toronto, Ontario M5S 3E2, Canada; Faculty of Physical Education and Health [S.G.T.], University of Toronto, Toronto,
\end{abstract}

Ontario M5S 2W6, Canada

\begin{abstract}
Television viewing (TVV) is considered a contributing factor to the development of childhood obesity yet it is unclear whether obesity results, in part, from increased energy intake during TVV. The objective of this study was to determine the effect of TVV on food intake (FI) of boys at a meal and its effect on caloric compensation at the test meal after a premeal glucose drink. On four separate mornings and in random order, boys received equally sweetened preloads containing Splenda sucralose or glucose $[1.0 \mathrm{~g} / \mathrm{kg}$ body weight (BW)] in $250 \mathrm{~mL}$ of water $2 \mathrm{~h}$ after a standard breakfast. Food intake from a pizza meal was measured $30 \mathrm{~min}$ later with or without TVV. Both preload treatment $(p<0.01)$ and TVV $(p<0.001)$ affected FI (kcal). TVV increased lunchtime FI by an average of 228 kcal. Glucose suppressed FI in the no TVV condition compared with control, but the effect was not statistically significant during TVV. Body composition and subjective appetite scores were positively associated with FI at the test lunch. In conclusion, TVV while eating a meal contributes to increased energy intake by delaying normal mealtime satiation and reducing satiety signals from previously consumed foods. (Pediatr Res 61: 745-749, 2007)
\end{abstract}

$\mathrm{T}$ VV has been identified as one of the etiological factors contributing to obesity in children $(1,2)$. Canadian (3) and U.S (4) children spend an average of 14.1 and $20 \mathrm{~h} / \mathrm{wk}$, respectively, watching television (TV). Young children were reported to consume on weekday and weekend days, $18 \%$ and $26 \%$ of total daily energy, respectively, during TVV (5).

The amount of time watching TV and increased fatness of children is well documented $(1,2)$ and is associated with decreased energy expenditure and increased energy intake. Cross-sectional studies suggest that time spent watching TV is positively associated with increased energy intake. Based on self-reports, more frequent TVV (h/d) has been associated with higher energy intake in both women (6) and children (7). However, the direct effect of TVV while eating a meal remains uncertain.

Received September 12, 2006; accepted January 31, 2007.

Correspondence: G. Harvey Anderson, Ph.D., University of Toronto, Department of Nutritional Sciences, Faculty of Medicine, 3rd Floor, FitzGerald Building, 150 College Street, Toronto, ON, Canada M5S 3E2; e-mail: harvey.anderson@utoronto.ca

Supported by an operating grant from the Canadian Institute of Health Research (grant MOP-64430) and a scholarship to N.B. from the Danone Institute of Canada.

DOI: $10.1203 /$ pdr.0b013e3180536591
Recent indirect studies have attempted to characterize whether eating in front of the TV has adverse effects on macronutrient selection and energy intake. Children from families with frequent compared with infrequent TVV during meals reported lower carbohydrate intake (\% of energy), but no significant difference in total energy intake (8). Similarly, undergraduate students on days when they viewed TV while eating reported an increase in meal frequency and a decrease in between-meal intervals, but no difference in energy intake compared with days when they did not watch TV (9). Adolescent boys reported that $400 \mathrm{kcal} / \mathrm{d}$ were consumed from snacks and sweetened beverages on TVV days (10), but snacking on nonTVV days was not reported, leaving uncertain whether eating while watching TV increases energy intake.

Only recently has the effect of TVV on mealtime intakes been evaluated by within-subject comparisons, and the results suggest TVV disrupts energy intake regulation. Three- to 5-y-old children consumed less total weight of food from a snack and meal in the TV condition compared with the no TV condition (11). However, the children who reported a greater frequency of watching TV at mealtime ate more at the lunchtime condition during TVV, suggesting that they ignored internal cues of satiety and that satiation was delayed. The observation that undergraduate students have decreased intermeal intervals on days they watch TV (9) also suggests that the duration of satiety after previously consumed food is reduced.

Evidence that physiologic signals of satiety may be compromised by TVV is suggested from studies showing excellent caloric compensation at test meals after sugar preloads in children. Energy intake at a meal after a caloric preload has been used frequently to examine short-term satiety signals of FI in adults $(12,13)$ and in children $(14-17)$. Normal weight preschool children $(14,15)$ and 2- to 4-y-old boys (16) given either sucrose, low glucose maltodextrin, or a combination of both reduced their intake in the test meal by an amount approximating the energy content of the preloads when provided unlimited access to a test meal within the first $30 \mathrm{~min}$ after the preloads.

No within-subject studies have been reported on the effect of TVV at mealtime on FI in older children. In addition, the interaction between TVV and physiologic

Abbreviations: BW, body weight; FI, food intake; FFM, fat free mass; FM, fat mass; PFC, prospective food consumption; VAS, visual analogue scale 
signals in the regulation of energy intake has not been addressed directly. Therefore, the objective of this study was to determine the effect of TVV on FI at a meal after 9to 14-y-old boys were exposed to a caloric (glucose) or noncaloric preload condition.

\section{METHODS}

Subjects. Fourteen boys between the ages of 9 and 14 y participated in this study (Table 1). Because there are no Canadian body mass index (BMI) references for children, Centers for Disease Control and Prevention (CDC) BMI charts are recommended for monitoring individual Canadian children (18). Eleven boys were between the 5th and 85th (normal weight), one boy was between the 85th and 95th (overweight), and two boys were greater than the 95th (obese) age- and sex- specific BMI percentiles according to the Canadian interpretation (18) of the CDC growth charts (19). Boys were recruited via a letter sent home to parents through the schools and by word-of-mouth. The Human Subjects Review Committee (University of Toronto and North York General Hospital) approved this study.

To participate, boys had to have been born at full term and normal weight. Individuals dieting, taking medication, and with any significant learning, behavioral, or emotional difficulties were excluded. Parents who volunteered their children completed, by telephone, a semistructured interview designed to elicit information about the inclusion and exclusion criteria. If a child met the study requirements, a screening session was arranged for the parent and child. During the screening session, the study was explained to the child and parent. Informed consent was obtained from the parent and assent was obtained from the child. Boys were familiarized with the visual analogue scale (VAS) questionnaires and asked to select the type of pizza they would eat during the test visits.

Study design and procedures. A within-subjects $2 \times 2$ factorial design was used to examine children's lunch intake after preload treatments, with and without TVV. Subjects were randomly selected into a particular treatment order and the treatment order was balanced. On four separate mornings, in random, boys were given equally sweetened preloads of a Splenda sucralose control or $1.0 \mathrm{~g} / \mathrm{kg} \mathrm{BW}$ glucose in $250 \mathrm{~mL}$ of water $2 \mathrm{~h}$ after a standard breakfast of milk, cereal, and orange juice. The boys were then given a pizza lunch $30 \mathrm{~min}$ later, with or without TVV, and allowed to eat until they were comfortably full.

Experimental procedures. Boys arrived at the Department of Nutritional Sciences at 1000 or $1100 \mathrm{~h}, 2 \mathrm{~h}$ after the consumption of a standard breakfast of Parmalat fat-free skim milk ( $250 \mathrm{~mL}, 91 \mathrm{kcal})$, Honey Nut Cheerios $(26 \mathrm{~g}$, $103 \mathrm{kcal})$, and Tropicana orange juice $(236 \mathrm{~mL}, 110 \mathrm{kcal})$ at home $(0800$ or $0900 \mathrm{~h}$ ). Upon arrival, subjects completed baseline VAS questionnaires rating their motivation to eat and physical comfort $(12,20,21)$. The motivation-to-eat VAS was also administered at 15,30 , and $75 \mathrm{~min}$. The physical comfort VAS was administered once at baseline and again at $75 \mathrm{~min}$, after completion of the test meal. Four other VAS questionnaires were administered to assess sweetness and pleasantness of test beverages, pleasantness of the pizza lunch, and enjoyment of the cartoon program.

Two equally sweetened drinks containing glucose monohydrate (Grain Process Enterprises, Toronto, ON, Canada) and a sweetened control were

Table 1. Baseline characteristics of test subjects

Subject characteristics

$\begin{array}{lc}\text { Age }(\mathrm{y}) & 12.6 \pm 0.4 \\ \text { Body weight }(\mathrm{kg}) & 49.9 \pm 3.1 \\ \text { Height }(\mathrm{m}) & 1.55 \pm 0.03 \\ \mathrm{BMI}\left(\mathrm{kg} / \mathrm{m}^{2}\right) & 20.4 \pm 0.9 \\ \text { BMI percentile range } & 10-97 \\ \sum \text { skinfolds }(\mathrm{mm}) * & 61.6 \pm 7.1 \\ \text { Fat mass }(\%) \dagger & 25.9 \pm 1.3 \\ \text { Fat mass }(\mathrm{kg}) \dagger & 13.2 \pm 1.3 \\ \text { Fat-free mass }(\%) & 74.1 \pm 1.3 \\ \text { Fat-free mass }(\mathrm{kg}) & 36.7 \pm 2.1\end{array}$

Data are means \pm SEM, $n=14$.

* Skinfold thickness was measured by Cambridge Scientific skinfold calipers (the sum of biceps, triceps, suprailial, and subscapular skinfold thickness, $\mathrm{mm}$ ), recorded to the nearest $0.1 \mathrm{~mm}$.

$\dagger$ Fat mass was determined from the sum of skinfold measurements at four points. administered. Treatments were matched for sweetness and flavor by adding the high-intensity sweetener Splenda sucralose (donated by Tate and Lyle Sucralose, Inc., Decatur, IL) because it is not metabolized in the body and does not alter blood glucose or insulin secretion (22). In addition, aspartamesweetened, cherry-flavored crystals (1.1 g, Sugar-Free Kool-Aid, Kraft Canada Inc., Don Mills, ON, Canada) were added to standardize flavor among test treatments. Test preloads were stored in the refrigerator and served chilled to subjects the following morning. Subjects consumed their treatments, followed by $50 \mathrm{~mL}$ of water to minimize aftertaste, in $\leq 5 \mathrm{~min}$. Preload drinks were served in a covered, opaque cup at 1015 or $1115 \mathrm{~h}$, and a pizza lunch was provided $30 \mathrm{~min}$ later for $45 \mathrm{~min}$. During the first $30 \mathrm{~min}$ after consumption of test preloads, boys engaged in child-appropriate games. At $30 \mathrm{~min}$, boys were escorted into the taste panel room and individually seated in their own cubicle, free of external cues. They were served a pizza lunch along with a 500-mL bottled spring water (Danone Crystal Springs). During the TVV conditions, boys watched a cartoon program on a 15 -in. TV and were provided with headphones so as not to disturb other boys in adjacent cubicles eating lunch. The TV program was on only during lunch.

Two varieties of Deep ' $N$ Delicious 5-in. diameter pizza were fed; pepperoni and three-cheese pizzas were donated by McCain Foods (McCain Canada Ltd., Florenceville, Canada). Pepperoni pizza slices (102 g) contained $11 \mathrm{~g}$ of protein, $6 \mathrm{~g}$ of fat, and $27 \mathrm{~g}$ of carbohydrate $(210 \mathrm{kcal})$. Similarly, each three-cheese pizza slice $(96 \mathrm{~g}$ ) contained $12 \mathrm{~g}$ of protein, $7 \mathrm{~g}$ of fat, and $30 \mathrm{~g}$ of carbohydrate $(230 \mathrm{kcal})$. The cooked pizzas were weighed and cut into four equal pieces before serving, and the amount left after the meal was subtracted from the initial weight to provide a measure of FI. The boys were informed that additional hot trays would be presented at regular intervals and were instructed to eat until they were "comfortably full." A freshly baked tray of pizza was provided to boys starting at $30 \mathrm{~min}$ and at 41,52 , and $63 \mathrm{~min}$ after consumption of the preloads. After a fresh tray was provided, the previous tray was removed. For all sessions, boys remained in the taste panel room for $45 \mathrm{~min}$. Each variety of pizza was weighed separately and the energy consumed (in kcal) was calculated by converting the net weight consumed to kcal consumed by use of information provided by the manufacturer (McCain Food Ltd.). An advantage of using these pizzas was the lack of an outer crust, which resulted in a pizza with a uniform energy content and eliminated the possibility that the subject will eat the more energy dense filling and leave the outside crust of the pizza. The bottled water was weighed before and after the test meal to calculate the net amount ingested. Upon termination of the meal, subjects completed the postmeal motivation-to-eat, physical comfort, and pleasantness of the pizza meal VAS questionnaires.

Measures. The motivation-to-eat VAS questionnaire, used to assess appetite, was composed of four questions or scales: (1) How strong is your desire to eat? ("very weak" to "very strong"), (2) How hungry do you feel? ("not hungry at all" to "as hungry as I've ever felt"), (3) How full do you feel? ("not full at all" to "very full"), and (4) How much food do you think you can eat? (prospective food consumption, PFC) "nothing at all" to "a large amount" $(12,21,23,24)$.

Sweetness, pleasantness of test beverages/pizza lunch, and physical comfort were measured using a VAS $(20,21,23)$. To measure sweetness, the question "How sweet have you found the beverage?" could be answered anywhere on a line anchored at the beginning and end by statements "not at all sweet" and "very sweet". Pleasantness of the test beverages/pizza lunch was measured by answers to the question "How pleasant have you found the beverage/pizza lunch?" that ranged from "not at all pleasant" to "very pleasant." Similarly, physical comfort was assessed, at baseline and at $60 \mathrm{~min}$ after consumption of the test meal, by answers to the question "How well do you feel?" that could range from "not well at all" to "very well."

During each of the two TVV conditions, boys watched two episodes (45 min) of The Simpsons (The Complete Fourth Season, Twentieth Century Fox Home Entertainment, Inc.). There were four episodes in total so that each child watched, in random order, all four cartoons during the study. Because 9- to 11-y-old children consumed more food (g) after a 10-min cartoon with food adverts compared with a cartoon with nonfood related adverts, ads were removed (25). After the two TVV conditions, children completed a TVV questionnaire to assess their enjoyment of the TVV program with the following question: "How well did you enjoy the cartoon program?" ("not well at all" to "very well").

Anthropometric measurements including height $(\mathrm{m})$, weight $(\mathrm{kg})$, and triceps, biceps, suprailial, and subscapular skinfold thickness (mm) were obtained by standard procedures (26). BMI $\left(\mathrm{kg} / \mathrm{m}^{2}\right)$ was calculated for each boy. Skinfold thickness was measured by skinfold calipers (Cambridge Scientific Industries, Cambridge, MD) recorded to the nearest $0.1 \mathrm{~mm}(27)$. The mean of three consecutive skinfold measurements was used for statistical analysis. Estimates of body fat from skinfold measurements were predicted from age- and sex-specific regression equations (28). 
An average appetite score was calculated at each time of measurement for each preload treatment by the formula: Appetite score $(\mathrm{mm})=[$ desire to eat + hunger $+(100-$ fullness $)+\mathrm{PFC}] / 4$, which reflects the four questions on the motivation-to-eat VAS as used previously $(12,20-23)$.

Caloric compensation was calculated for each person by the following formula $(17,29)$ : Compensation $(\%)=[$ Control intake $(\mathrm{kcal})-$ Treatment intake $(\mathrm{kcal}) / \mathrm{kcal}$ in treatment preload] $\times 100$.

A compensation score of $100 \%$ indicates perfect compensation, that is, a $50-\mathrm{kg}$ boy would reduce his lunch intake by $200 \mathrm{kcal}$ on days when they were given the calorie-containing $(1 \mathrm{~g} / \mathrm{kg}, 200 \mathrm{kcal})$ preload (treatment) compared with days when they were given the control preload. Compensation scores $<100 \%$ indicate overconsumption at the test meal, whereas scores $>100 \%$ indicate underconsumption at the test meal.

Data analysis. Food and water intake and VAS data were analyzed using as a within-subjects repeated-measures $2 \times 2$ factorial design using the PROC MIXED procedure with preload treatment (control and glucose) and TVV (no TVV or TVV) as main factors. Subjective appetite data were further analyzed to assess the effect of time $(0,15,30$, and $75 \mathrm{~min})$. Preliminary models included all interactions; however, nonsignificant interactions were removed sequentially from the model. Post hoc analysis by the Tukey-Kramer test, adjusted for multiple comparisons, was performed when treatment effects were found to be statistically significant at $p<0.05$. Analysis of the TVV enjoyment VAS was analyzed by paired $t$ test and statistical significance was defined as $p<0.05$. Correlations on dependent measures were conducted by use of Pearson correlation coefficients. Statistical Analysis Software (SAS) version 9.1 (SAS Institute Inc., Cary, NC) was used to perform statistical analyses.

\section{RESULTS}

Food and water intake at lunch. Preload treatment and TVV affected energy consumption at the test meal when FI was expressed in grams (Fig. 1A) (preload treatment, $p<$ 0.01 ; TV,$p<0.001)$ or when converted to kilocalories (Fig. $1 B$ ) (preload treatment, $p<0.01$; TVV, $p<0.001$ ). TVV in the eating environment increased lunchtime FI by 228 $\mathrm{kcal}$. Boys reduced their FI at the pizza lunch after the glucose preload in the no TVV condition, but did not respond as well to the energy content of the glucose preload in the TVV condition.
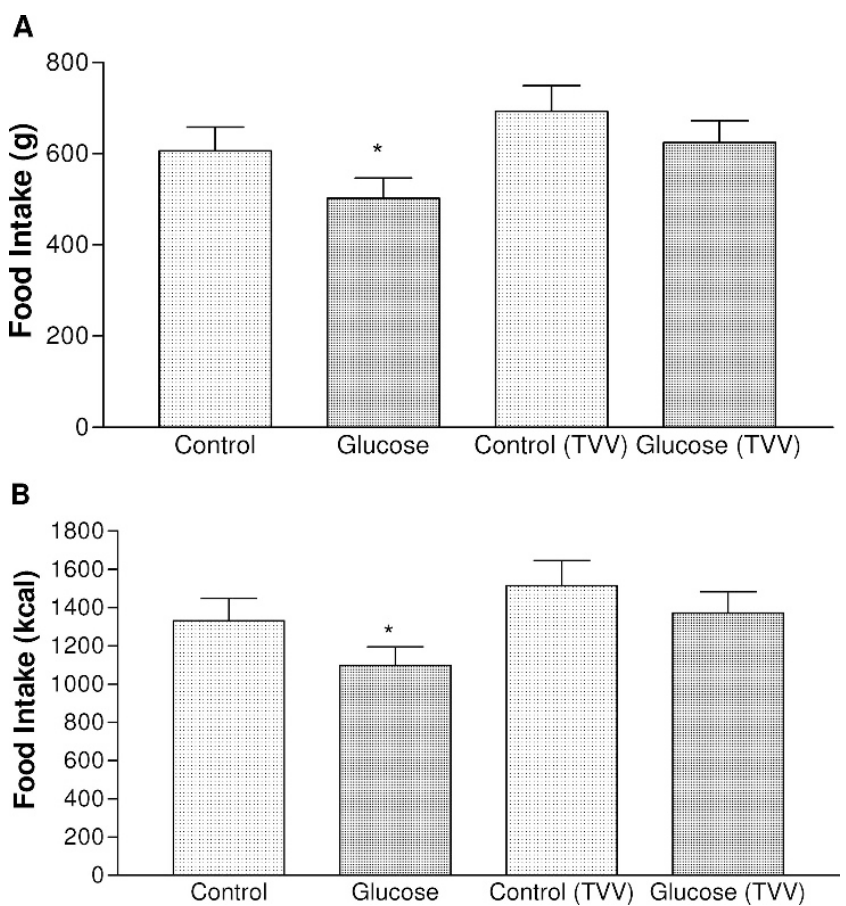

Figure 1. FI at a test meal $30 \mathrm{~min}$ after preload treatments with or without TVV in boys. Food intake in grams $(A)$ and in kilocalories $(B)$ measured 30 min later after the control (dotted columns) and glucose (shaded columns) preloads. $* p<0.05 v s$ all treatments.
Table 2. Effect of preload treatments on FI 30 min later with or without TVV

\begin{tabular}{|c|c|c|c|c|}
\hline & \multicolumn{2}{|c|}{ No TVV } & \multicolumn{2}{|c|}{ TVV } \\
\hline & Control & Glucose & Control & Glucose \\
\hline Meal (g) & $606 \pm 52$ & $502 \pm 44^{*}$ & $693 \pm 56$ & $624 \pm 48$ \\
\hline Water (g) & $346 \pm 54$ & $284 \pm 48$ & $285 \pm 61$ & $277 \pm 50$ \\
\hline Meal + water $(\mathrm{g})$ & $952 \pm 101$ & $785 \pm 86 \dagger$ & $977 \pm 103$ & $901 \pm 81$ \\
\hline Meal (kcal) & $1332 \pm 117$ & $1097 \pm 97^{*}$ & $1514 \pm 132$ & $1371 \pm 111$ \\
\hline $\begin{array}{l}\text { Meal }+ \text { preload } \\
\quad(\mathrm{kcal})\end{array}$ & $1332 \pm 117+$ & $1297 \pm 106 \S$ & $1514 \pm 132$ & $1572 \pm 118$ \\
\hline $\begin{array}{l}\text { Caloric } \\
\quad \text { compensation }(\%)\end{array}$ & - & $112 \pm 38$ & - & $66 \pm 32$ \\
\hline
\end{tabular}

Data are means $\pm \mathrm{SEM}$

$* p<0.05$ versus all treatments.

$\dagger p<0.05$ versus control no TVV and control TVV.

$\ddagger p<0.05$ versus glucose TVV.

$\S p<0.05$ versus control TVV and glucose TVV.

Caloric compensation after the glucose preload was $112 \%$ in the no TVV condition compared with $66 \%$ during TVV (Table 2). Water intake at lunch was not affected by preload treatment $(p<$ $0.25)$ or by TVV $(p<0.27)$ (Table 2$)$. Cumulative [water $(\mathrm{g})$ plus FI $(\mathrm{g})]$ intake was affected by preload treatment $(p<$ $0.01)$, but not by TVV $(p<0.08)$. Cumulative (meal plus preload) intake was affected by TVV $(p<0.001)$, but not by preload treatment $(p<0.82)$.

Subjective average appetite scores. Neither preload treatment $(p<0.54)$ nor TVV $(p<0.33)$ affected average appetite scores, but time $(p<0.001)$ was a factor (Fig. $2 A)$. Of the individual VAS scores, time $(p<0.001)$ was a factor, but neither preload treatment nor TVV were factors affecting subjective appetite scores (Fig. 2B-E). After the test meal, desire to eat, hunger, and PFC were significantly reduced and fullness increased after all preload treatments.

Average appetite, desire to eat, hunger, and PFC were positively and fullness negatively associated with FI in boys. Correlations between the individual VAS and FI were found, at all times, for all scales in boys. At $30 \mathrm{~min}$, just before introduction of the test meal, PFC was the strongest $(r=0.55$, $p<0.001)$ and hunger $(r=0.34, p<0.05)$ was the weakest predictor of forthcoming FI in boys.

Relationships between body composition variables and FI. Measures of body composition including BW, fat mass (FM), and fat-free mass (FFM) were positively associated with FI. BW was positively associated with FI after the control and glucose treatments in the no TVV (control: $r=0.86, p<$ 0.001; glucose: $r=0.72, p<0.01$ ) and TVV (control: $r=$ $0.68, p<0.01$; glucose: $r=0.63, p<0.05$ ) conditions. FM was positively associated with FI in the no TVV (control: $r=$ 0.80, $p<0.001$ : glucose: $r=0.62, p<0.05)$ and TVV condition (control: $r=0.71, p<0.01$; glucose: $r=0.75, p<$ $0.01)$. FFM correlated positively with FI, but the correlations were stronger in the no TVV (control: $r=0.80, p<0.001$; glucose: $r=0.70, p<0.01$ ) compared with the TVV (control: $r=0.58, p<0.05$; glucose: $r=0.48, p<0.08$ ) condition.

Subjective ratings of physical comfort, sweetness, pleasantness, and enjoyment of the TVV program. Neither preload treatment $(p<0.57)$ nor TVV $(p<0.43)$ were factors 

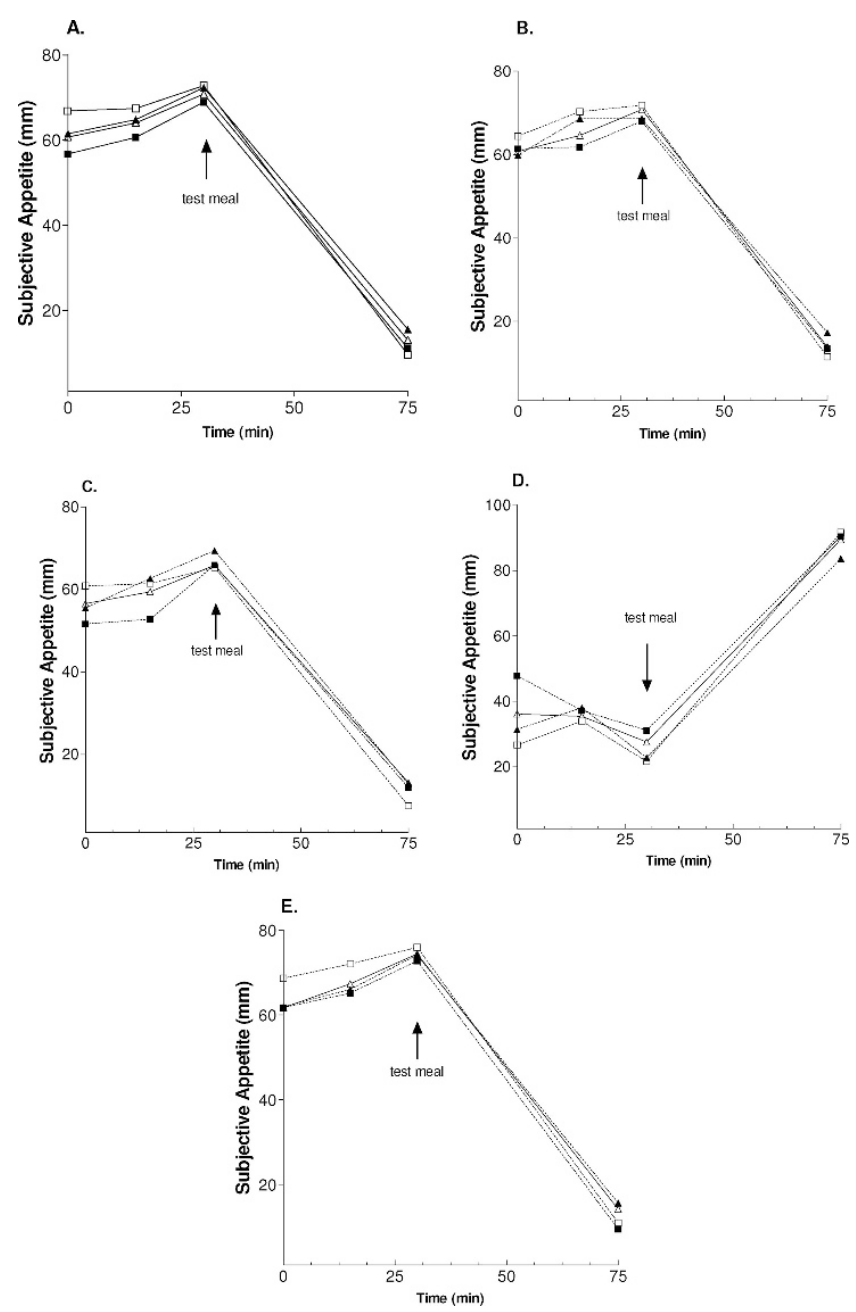

Figure 2. Subjective appetite after preload treatments with or without TVV. Average appetite $(A)$, desire to eat $(B)$, hunger $(C)$, fullness $(D)$, and PFC $(E)$ at $0,15,30$, and $75 \mathrm{~min}$ after the control (filled squares), glucose (filled triangles), control TVV (open squares) and glucose TVV (open triangles) treatments. Time affected average and individual appetite scores $(p<0.001)$.

affecting physical comfort, reported as the change from baseline, and pleasantness of the preloads or test meal (Table 3 ). However, there was a preload treatment $(p<0.05)$ effect on

Table 3. Subjective ratings of physical comfort, sweetness, pleasantness of the preloads and test meal, and enjoyment of the TVV program

\begin{tabular}{lccccc}
\hline & \multicolumn{2}{c}{ No TVV } & & \multicolumn{2}{c}{ TVV } \\
\cline { 2 - 3 } \cline { 5 - 6 } & Control & Glucose & & Control & Glucose \\
\hline $\begin{array}{c}\Delta \text { Physical } \\
\text { comfort* }\end{array}$ & $-8.5 \pm 3.6$ & $-10.4 \pm 5.0$ & & $-11.4 \pm 5.8$ & $-14.2 \pm 6.1$ \\
$\begin{array}{c}\text { Sweetness of } \\
\text { preloads }\end{array}$ & $63.7 \pm 7.4$ & $84.0 \pm 3.4 \dagger$ & $76.2 \pm 4.4$ & $76.0 \pm 5.0$ \\
$\begin{array}{c}\text { Pleasantness of } \\
\text { preloads }\end{array}$ & $49.4 \pm 7.2$ & $65.6 \pm 6.3$ & & $70.2 \pm 6.6$ & $66.5 \pm 6.2$ \\
$\begin{array}{c}\text { Pleasantness of } \\
\text { test meal }\end{array}$ & $77.5 \pm 4.3$ & $75.8 \pm 4.1$ & & $78.1 \pm 3.8$ & $74.8 \pm 5.1$ \\
TVV enjoyment & - & - & $73.2 \pm 8.5$ & $59.3 \pm 9.9$ \\
\hline
\end{tabular}

Data are means $(\mathrm{mm}) \pm$ SEM.

* Physical comfort is reported as the change from baseline (physical comfort at $75 \mathrm{~min}-$ physical comfort at $0 \mathrm{~min}$ ).

$\dagger p<0.01$ versus control no TVV. subjective sweetness. In the no TVV condition, subjective sweetness of the glucose preload was significantly higher than the control by $20.3 \pm 5.5 \mathrm{~mm}(p<0.01)$. Enjoyment of the TVV program was not different between the control and glucose (Table 3) treatments, and there was no association between enjoyment of the TVV program and FI at the test lunch $(r=0.08, p<0.69)$.

\section{DISCUSSION}

The results from this study show that lunchtime energy intakes are increased and FI control is diminished when 9- to 14-y-old boys ate lunch in a TVV environment. The results also indicated that physiologic signals of satiation and satiety are overridden by TVV.

To assess whether TVV in the eating environment altered FI control in response to previously consumed calories we used a preload design. The preload design provides a framework to measure the role of physiologic signals affecting both satiation (factors in a meal that bring eating to an end) and satiety (absence of hunger) signals from glucose preloads (30). FI was not lower due to previous consumption of the glucose load during the TVV condition, which shows that the effect of glucose on satiety was diminished and also suggests that higher energy intake (averaging $228 \mathrm{kcal}$ ) during TVV was due to delayed satiation. TVV may have increased energy intake by distracting boys from physiologic satiety signals of the glucose preload and satiation of the pizza lunch or by drawing attention away from their habitual control of FI. These data are consistent with those of a previous study in which normal-weight women ate $72 \mathrm{kcal}$ more when they listened to an audio story compared with the baseline condition (31).

Higher energy intake by 9- to 14-y-old boys during TVV is in contrast to the lower FI reported in 3- to 5-y-old children (11). The preschool children consumed lower total weight of food at snack time and lunchtime while watching a 22-min cartoon program compared with a no TVV condition. During the test conditions, children were offered a variety of foods that varied in energy, and it is unclear why the authors did not report energy intakes (kcal), which would have controlled for differences in the energy density of the test foods and provided a clearer picture of the role of TVV on FI control.

Lower FI after consuming the glucose load in the no TVV condition compared with the sweet control is consistent with previous studies of normal-weight adult men (12) and children (14-16). It is possible that a sustained response would have prevailed if a solid rather than a liquid preload had been consumed. However, at present, there is little evidence that liquid sugars suppress FI less than solid forms (32). Furthermore, caloric compensation in the current study was $112 \%$ in the no TVV condition (Table 2) and higher than the response in normal-weight adult men (12). These results support previous observations suggesting that young children adjust more fully for calories consumed as carbohydrates than do adults (33) and that glucose in liquid form does not bypass FI regulatory mechanisms (32). 
Subjective appetite measures in these children showing that they failed to report a decrease in subjective appetite after the preload are consistent with our previous observations (23). Although this might be taken to suggest that children are not able to complete a VAS in a quantitative manner that is reflective of their actual feeling of appetite, this seems unlikely because in both the previous (23) and current studies, the test meals resulted in large decreases in reported desire to eat, hunger, and PFC and increased fullness independent of the preload treatments.

Subjective appetite scores often correlate with FI after carbohydrate preloads in normal-weight adult men $(12,20,21,34)$. In the current study, PFC at $30 \mathrm{~min}$ was the strongest $(r=0.55, p<0.001)$ and hunger was the weakest $(r=0.34, p<0.05)$ predictor of FI in boys. In adults, hunger is the strongest and PFC is the weakest predictor of FI (35), indicating that subjective expressions of appetite differ between adults and children.

Body composition was measured in this study because FM has been found to affect caloric compensation to preloads given in fixed amounts without consideration to the body size of the child. FM in 2- to 4-y-old girls but not boys was inversely associated with caloric compensation to carbohydrates given as a fixed-size preload (16). However, the present study shows that BW, FM, and FFM were equally positively associated with FI, but not with compensation after the glucose preload, in each treatment condition. That is, the larger the body size, the greater the FI at the meal, and the variation in body composition was not a significant factor. However, body size did not affect compensation to the glucose preload because it was provided on a BW basis. The decrease in FI when glucose was given on a BW basis was consistent across body size and composition, but the response was compromised solely due to the TVV condition.

In addition to body fat being a variable in caloric compensation, sex is also a likely variable (16). Girls of this age will be entering the most active growth phase (12 y), menarche, and it is probable that satiety, FI, and eating behaviors are affected by the development of the menstrual cycle. Furthermore, women, in contrast to men, show a differential response to dietary fat accessibility as measured by both cholecystokinin release and subjective measures of appetite (36).

In conclusion, TVV by boys while eating a meal contributes to increased energy intake and it does so by delaying normal mealtime satiation and reducing satiety signals from previously consumed foods.

Acknowledgments. The authors thank Benson Fong and Thomas Dobosz for help with the project.

\section{REFERENCES}

1. Dietz WH Jr, Gortmaker SL 1985 Do we fatten our children at the television set? Obesity and television viewing in children and adolescents. Pediatrics 75:807-812

2. Robinson TN 1999 Reducing children's television viewing to prevent obesity: a randomized controlled trial. JAMA 282:1561-1567

3. Canada S 2006 Television Viewing: Data Tables. Statistics Canada, Ottawa, Canada, Catalogue no. 87F0006XIE
4. Nielsen Media Research 20002000 report on television: the first 50 years. AC Nielsen Co., New York

5. Matheson DM, Killen JD, Wang Y, Varady A, Robinson TN 2004 Children's food consumption during television viewing. Am J Clin Nutr 79:1088-1094

6. Jeffery RW, French SA 1998 Epidemic obesity in the United States: are fast foods and television viewing contributing? Am J Public Health 88:277-280

7. Robinson TN 2001 Television viewing and childhood obesity. Pediatr Clin North Am 48:1017-1025

8. Coon KA, Goldberg J, Rogers BL, Tucker KL 2001 Relationships between use of television during meals and children's food consumption patterns. Pediatrics 107:E7

9. Stroebele N, de Castro JM 2004 Television viewing is associated with an increase in meal frequency in humans. Appetite 42:111-113

10. Van den Bulck J, Van Mierlo J 2004 Energy intake associated with television viewing in adolescents, a cross sectional study. Appetite 43:181-184

11. Francis LA, Birch LL 2006 Does eating during television viewing affect preschool children's intake? J Am Diet Assoc 106:598-600

12. Anderson GH, Catherine NL, Woodend DM, Wolever TM 2002 Inverse association between the effect of carbohydrates on blood glucose and subsequent short-term food intake in young men. Am J Clin Nutr 76:1023-1030

13. Anderson GH, Tecimer SN, Shah D, Zafar TA 2004 Protein source, quantity, and time of consumption determine the effect of proteins on short-term food intake in young men. J Nutr 134:3011-3015

14. Birch LL, McPhee L, Sullivan S 1989 Children's food intake following drinks sweetened with sucrose or aspartame, time course effects. Physiol Behav 45:387-395

15. Birch LL, McPhee L, Steinberg L, Sullivan S 1990 Conditioned flavor preferences in young children. Physiol Behav 47:501-505

16. Johnson SL, Birch LL 1994 Parents' and children's adiposity and eating style. Pediatrics 94:653-661

17. Black RM, Anderson GH 1994 Sweeteners, food intake and selection. In: Appetite and Body Weight Regulation: Sugar, Fat, and Macronutrient Substitutes. CRC Press, Boca Raton, FL, pp 125-136

18. Dietitians of Canada, Canadian Paediatric Society, College of Family Physicians of Canada, \& Community Health Nurses Association of Canada 2004 The use of growth charts for assessing and monitoring growth in Canadian infants and children. Can J Diet Pract Res 65:22-32

19. Ogden CL, Kuczmarski RJ, Flegal KM, Mei Z, Guo S, Wei R, Grummer-Strawn LM, Curtin LR, Roche AF, Johnson CL 2002 Centers for Disease Control and Prevention 2000 growth charts for the United States: improvements to the 1977 National Center for Health Statistics version. Pediatrics 109:45-60

20. Woodend DM, Anderson GH 2001 Effect of sucrose and safflower oil preloads on short term appetite and food intake of young men. Appetite 37:185-195

21. Anderson GH, Woodend D 2003 Effect of glycemic carbohydrates on short-term satiety and food intake. Nutr Rev 61:S17-S26

22. Duffy VB, Anderson GH 1998 Position of the American Dietetic Association: use of nutritive and nonnutritive sweeteners. J Am Diet Assoc 98:580-587

23. Anderson GH, Saravis S, Schacher R, Zlotkin S, Leiter L 1989 Aspartame: effect on lunch-time food intake, appetite and hedonic response in children. Appetite 13:93103

24. Stubbs RJ, Hughes DA, Johnstone AM, Rowley E, Reid C, Elia M, Stratton R, Delargy H, King N, Blundell JE 2000 The use of visual analogue scales to assess motivation to eat in human subjects: a review of their reliability and validity with an evaluation of new hand-held computerized systems for temporal tracking of appetite ratings. Br J Nutr 84:405-415

25. Halford JC, Gillespie J, Brown V, Pontin EE, Dovey TM 2004 Effect of television advertisements for foods on food consumption in children. Appetite 42:221-225

26. Heymsfield SB, Williams PJ 1988 Nutritional assessment by clinical and biochemical methods. In: Shils M, Young V (eds) Modern Nutrition in Health and Disease. Lea \& Febiger, Philadelphia, pp 817-860

27. Archibald EH, Harrison JE, Pencharz PB 1983 Effect of a weight-reducing highprotein diet on the body composition of obese adolescents. Am J Dis Child 137:658-662

28. Brook CG 1971 Determination of body composition of children from skinfold measurements. Arch Dis Child 46:182-184

29. Birch LL, Deysher M 1985 Conditioned and unconditioned caloric compensation: evidence of self-regulation of food intake by young children. Learn Motiv 16:341355

30. Gerstein DE, Woodward-Lopez G, Evans AE, Kelsey K, Drewnowski A 2004 Clarifying concepts about macronutrients' effects on satiation and satiety. J Am Diet Assoc 104:1151-1153

31. Bellisle F, Dalix AM 2001 Cognitive restraint can be offset by distraction, leading to increased meal intake in women. Am J Clin Nutr 74:197-200

32. Anderson GH 2006 Sugars-containing beverages and post-prandial satiety and food intake. Int J Obes (Lond) 30:S52-S59

33. Birch LL, Deysher M 1986 Caloric compensation and sensory specific satiety: evidence of self-regulation of food intake by young children. Appetite 7:323-331

34. Rogers PJ, Carlyle JA, Hill AJ, Blundell JE 1988 Uncoupling sweet taste and calories: comparison of the effects of glucose and three intense sweeteners on hunger and food intake. Physiol Behav 43:547-552

35. Drapeau V, Blundell J, Therrien F, Lawton C, Richard D, Tremblay A 2005 Appetite sensations as a marker of overall intake. Br J Nutr 93:273-280

36. Burton-Freeman B, Davis PA, Schneeman BO 2004 Interaction of fat availability and sex on postprandial satiety and cholecystokinin after mixed-food meals. Am J Clin Nutr 80:1207-1214 